\title{
MYOSITIS FIBROSA GENERALISATA
}

\author{
BY \\ A. M. STEWART and A. R. MACGREGOR \\ From the Departments of Surgery and Child Life and Health, University of Edinburgh
}

(Received for Publication August 10, 1950)

Myositis fibrosa generalisata is one of the rarest of the diseases of the muscular system. The number of authentic cases in the literature is small, and it is the purpose of this article to review the literature and to add a further case which has many features in common with those already described.

The onset of the disease is insidious. The patient usually complains of stiffness in one of the limbs, more often a lower limb. This stiffness is unaccompanied by pain but it is progressive and interferes with normal voluntary movement. Examination of the affected muscle reveals the presence of a small, painless, indurated area, which spreads until the whole muscle belly becomes involved. Similar areas appear in other muscles at a later date. All the affected muscles are firmer than normal. At first, the volume of the muscle remains unaltered, but later there is a marked diminution, with concomitant hardening of muscle texture. With the shortening of the muscle tendons, contractures develop and the patient becomes markedly deformed. There is progressive limitation of active and passive movements. In severe cases, the patient soon becomes bedridden.

As a rule, the facial muscles and sphincters are not involved. The masseter muscle is sometimes an exception and this interferes with movement of the jaw. The skin is never affected, a fact that distinguishes this disease from dermato-myositis.

In the initial stages there is an acute phase with rapid involvement of muscle groups, although little interference with general health is experienced. This stage is followed by periods of exacerbation and remission during which the patient may regain some muscle function. In some cases the whole course of the disease is more rapid.

Two features are important: there is neither fever nor pain.

The affected muscle responds to faradism but is hypotonic. Examination of the central nervous system shows no abnormality. Under anaesthesia the muscles retain their firm texture, and passive movement is limited by the degree of muscle contracture.
A definite diagnosis can be made only by microscopical examination of the muscle tissue. This shows hyaline degeneration, loss of cross striation and great variation in size of the muscle fibres. There is usually much increase of fibrous tissue, which surrounds and invades the involved muscle fibres. Round-cell infiltration may, or may not, be present.

Biochemical examination of affected muscle has shown a reduction in creatine content.

Treatment is, unfortunately, not satisfactory. No drug up to the present time has been found to be of any real value, although Blau (1938), recorded some relief from the use of glycocol. Physiotherapy and massage can be of benefit both from a psychological and a therapeutic aspect.

The prognosis is poor. In a later stage of the disease there is a progressive loss of weight and deterioration in well-being, and most of the patients die ultimately from intercurrent infection.

\section{Review of the Literature}

On a search of the literature, 11 authentic cases were observed: five patients contracted the disease in childhood and six in adult life. There are reports of a further five or six which can be regarded as atypical.

Onset during Infancy or Childhood. Janicke (1895) was the first author to describe the condition in detail. His patient was a three-year-old illegitimate girl. A small, firm nodule was felt in the left sternomastoid muscle. This nodule enlarged until the whole muscle belly became indurated. Subsequently, similar swellings appeared in other muscle bellies throughout the body. Three months after the onset of the disease all the affected muscles, with the exception of the pectoral group and the right biceps, had returned to almost normal consistence. Later, however, the right trapezius muscle again became indurated and this was followed by involvement of the right rectus abdominis muscle. Stab and streak cultures, prepared from muscle tissue fluid, were sterile. A biopsy specimen was taken from the right biceps, and it was noticed 
that there was a pronounced grating of the knife as the specimen was cut. Janicke gave a masterly description of the microscopic appearances. There was marked variation in the size of the individual muscle fibres, normal breadth and cross striations were rare, and many of the fibres were grossly swollen. Between these fibres atrophied muscle elements were prominent. Janicke considered that these findings showed distinct degenerative changes in the muscle parenchyma. There was marked alteration in the interstitial tissue, individual muscle fibres being forced apart by proliferating broad bands of dense, connective tissue. True cellular infiltration was not seen and the vessel walls were normal.

Litchfield (1903) described a case of widespread interstitial myositis in a girl of 4 years. This patient exhibited many of the characteristic features of myositis fibrosa generalisata but, in view of a strong family history of syphilis, the author considered that syphilis was responsible for the pathological changes in the muscles.

Batten (1904) described a case in a girl, aged 9 months, whose symptoms developed with involvement of muscles of the lower limbs and back, followed by similar changes in the right sternomastoid muscle and in muscles of the upper limbs and abdomen. At the age of 6 years the child was in a rigidly flexed position with the head tilted towards the right. Examination of the affected muscle after death showed fibrous tissue infiltration between the individual muscle fibres, many of which were atrophied and showed fatty degeneration.

In 1930 Price recorded a case of a girl of $3 \frac{1}{2}$ years, who reported with a hard, painless swelling in the right scapular region. This had fluctuated in size. Similar swellings appeared later in both sternomastoid muscles, the right brachialis and pectoralis major muscles. Biopsy from a pectoral muscle showed fibrous tissue, which had replaced and surrounded bundles of muscle fibres. There was no round-cell infiltration.

Schwab, Brindley, Bodansky, and Harris (1932) described a case of a Negro boy of 14 years, who reported with the history of a dull ache in the upper part of the chest wall, followed a few weeks later by stiffness and diminution in ability to use his hands. Similar symptoms appeared in the lower limbs. Eventually, almost all the muscles of the body were indurated, and the authors described the sensation, on palpation of these muscles, as not unlike a "sand-bag." The facial muscles were entirely unaffected with the exception of the masseter muscles, which were indurated. There was only slight involvement of the sternomastoid muscle. The strength of all the involved muscles was impaired. There was marked limitation of movement of upper and lower limbs. The boy was admitted to hospital at the age of 15 but died three months later with an infiltrative tuberculous lesion of the left lung. Biopsies of the muscle taken before death and tissue obtained at the post-mortem examination showed evidence of muscle degeneration, inflammation, and fibrous tissue proliferation. There was the usual variation in the size of individual muscle fibres, in many of which the striations had disappeared entirely: in other areas only longitudinal striations were present. Hyaline degeneration and hydropic infiltration were noticeable. There were varying numbers of inflammatory cells throughout the muscle tissue, some diffusely scattered, others arranged in collections around the more degenerated muscle fibres. Most of these cells were lymphocytes. Fibrous tissue of primitive type was present in varying amounts and occupied about $10 \%$ of the muscle volume. It is interesting to note that an examination of the myocardium showed a slight increase in the size of muscle fibres with granularity of the cytoplasm, an increase in fibrous tissue, and round-cell infiltration.

Blau (1938) placed a further case on record. A girl of 15 years complained of progressive limitation of movement in the joints of the limbs, accompanied by stiffness. Difficulty was experienced in using her hands and in walking upstairs. She was admitted to hospital at the age of 34 with atrophy of all skeletal muscles and generalized contractures limiting passive and active movements of the joints. The muscles were hard and inelastic. A biopsy from the left deltoid showed severe degenerative changes, fragmentation, and vacuolation of the individual muscle fibres. Cross striations were indistinct and occasional inflammatory cell infiltration was seen.

In 1941 Ellermann (1943) described a woman of 29 years, who had noticed a series of infiltrations in both thighs since childhood. Further swellings had appeared one year previously (1940), and the skin was found to be bound down to the deeper structures. There was no evidence of scleroderma. Biopsy was not convincing, but he considered, despite the very slight histological changes, that the condition was a true myositis fibrosa generalisata. This might be regarded more accurately as an atypical case.

We do not consider that the cases described by Schüller (1903) and Kagan (1936) fall into the category of this disease. A case described by Berghman (1874) is difficult to interpret but does not appear to resemble myositis fibrosa.

Onset in Adult Life. In 1923 Burton, Cowan, and Miller reviewed the literature and reported a total 
of three cases in which the condition had begun in adults-namely those of Gies (1879), Kreiss (1886) and Gowers (1899). In a more recent review by Schwab et al. (1932), some doubt was expressed as to whether these cases should be included as typical of the disease. In the patients described by Gies (1879) and Kreiss (1886) only the lower limbs were affected: there were skin changes and the extent of involvement was very limited. The authors considered that the symptoms described in Gower's (1899) patient could be explained by a diagnosis of peripheral neuritis rather than of myositis fibrosa generalisata. The authors added an additional case, a woman who complained of stiffness of the arms and legs at the age of 22 years. Three years later she was bedridden and markedly deformed. A biopsy of the left gastrocnemius muscle showed the usual histological findings with round-cell infiltration and, in addition, evidence of chronic arteritis. This patient improved but recrudescence followed a miscarriage. The case was reviewed again in 1931.

Schwab et al., in their review of the literature, found only four typical and about as many atypical cases. They include the case described by Hoover in 1924, which although apparently typical was not confirmed by biopsy. This patient lived for two years. They also state that Rosenstirn (1918) in his review of myositis ossificans progressiva found two further cases. They, however, consider them to be atypical.

Ornsteen (1935) described a case in a man of 42 years who suffered from severe muscle spasm, particularly when under a nervous strain, gradual stiffness in the back, and difficulty in walking. The abdominal muscles were also involved and no relaxation of these muscles was found during sleep. The diagnosis was supported by histological examination.

Blau (1938) reviewed the literature and reported a total of eight authentic cases. He added an additional two cases: one has already been described; the other occurred in a man of 20 years in whom there was rapid involvement of all the skeletal muscles including the masseter muscle. A biopsy of the left pectoralis major muscle showed the usual microscopical findings; cellular collections were present and irregular plaques of sclerotic fibrous connective tissue were seen in the sections examined.

Somers (1939) added a further case in a man of 53 years, who complained of stiffness in the lower extremities, spine, and abdominal wall. This case was proved by biopsy of the right quadriceps muscle.

Benedek (1944) reported a case resembling myasthenia but, from histological examination, it was considered to belong to the myositis fibrosa group.

Strong (1949) described a woman of 54 years, who had marked limitation of flexion and extension of the fingers in both hands. The forearm muscles were felt to be in spasm. Equinus and cavus deformity of the feet were notable features and obvious wasting of the calf muscles was present. A biopsy of the left flexor digitorum profundus showed muscle fibres to be thinner than normal with a definite diminution in cross striation. There was no evidence of fibrosis but some round-cell infiltration was seen. This case should also be regarded as an atypical example.

\section{Case History}

J.W., a boy, aged 11 years, was admitted in June, 1949.

The child was illegitimate and had been brought up by his mother, who was in very poor circumstances. So far as can be ascertained there was no family history of a similar condition. The patient was the second child of the family. Pregnancy, labour, and delivery were normal: and, at birth, no detectable abnormalities were present. At the age of 8 months he was seen at a neighbouring children's hospital as the mother had noticed that he was not using his left arm. He was otherwise perfectly normal and healthy and had never suffered from any febrile illness. Examination at that time showed a slight degree of atrophy of the left upper limb, together with limitation of supination. During the succeeding weeks this atrophy became more marked but all muscles were functioning normally. A Fairbank's splint was applied but the child did not report back for re-examination.

At the age of 5 years and 4 months the boy was admitted to the same hospital, having fractured his left femur as the result of a fall. The mother stated that the child had been late in sitting up, feeding, walking and talking. At that time it was noted that the left upper limb was atrophied and was used very little. He was also noticed to be mentally backward. Atrophy of the other limbs was not noted. The fractured femur united satisfactorily in good position but, according to the mother, the child had never walked since. A few years later he was certified as a mental defective and admitted to a home from which he was transferred to the Western General Hospital, Edinburgh. Unfortunately the mother was a very poor witness and it was not possible to obtain a more detailed history.

On admission, in June, 1949, the child appeared happy and contented. His intelligence was obviously well below normal, but this was difficult to assess as he had received little or no education. He was completely bedridden and unable to sit up or to feed himself. He was afebrile. He was extremely deformed, lying on his right side with his lower limbs flexed at all the joints. There was marked atrophy of all four limbs. The skin over the entire body was perfectly normal. Almost all the muscles of the upper and lower limbs were firm and 
indurated, and the tendons of these muscles stood out as tight bands, limiting joint movement and producing severe contractures. Both feet were in a marked equinus position and it was possible to dorsiflex the feet only slightly (Fig. 1a, b, and c). Extension of the knee joints was limited to just beyond a right angle, flexion of these joints also being interfered with although to a lesser extent. Passive extension of both hip joints was limited to about $110^{\circ}$; flexion, however, could take place to a greater extent. The upper limbs were less severely involved. Abduction of the shoulder was possible to

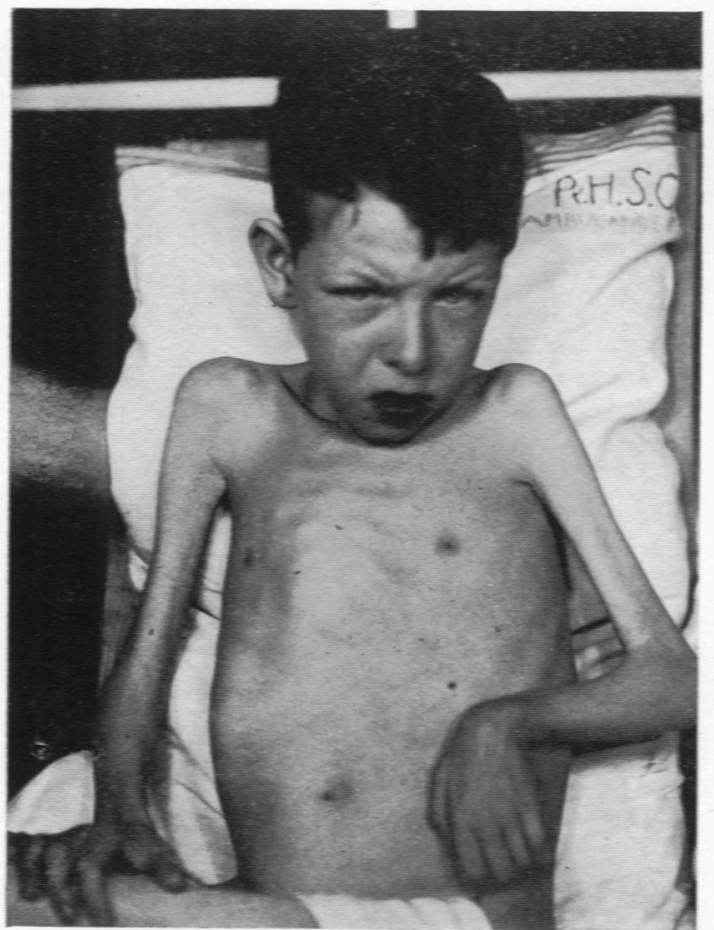

(a)

FIG. 1.

(a) On admission, showing deformities in the upper limbs.

(b) and (c) Comparison with normal child of same age.

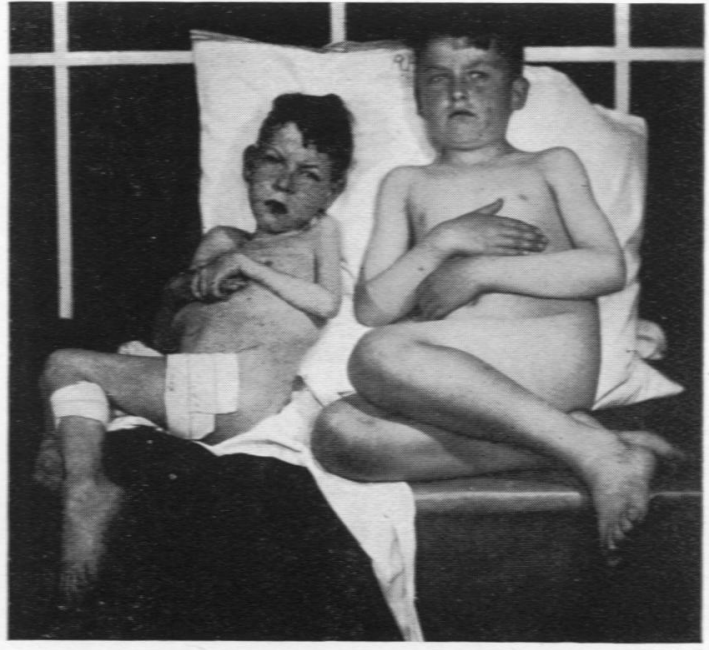

(b)

about $45^{\circ}$ and there was about $20^{\circ}$ movement of the elbow joint. There was ulnar deviation of both hands.

On palpation, the volume of the affected muscle was diminished; pain was not felt, although the child complained of discomfort on attempted extension of all joints beyond the ranges mentioned. These muscles had a curious, indurated feeling. Subcutaneous tissue moved freely over the surface of the muscle bellies. There was no involvement of the muscles of the face nor of the abdominal wall but those of the back felt firm and had the same texture as those of the limbs. All other systems were perfectly normal. It is necessary to emphasize that no abnormality was detected in the central nervous system. The child suffered from severe constipation with faecal impaction.

Special Investigations. The following laboratory and other investigations were made. 

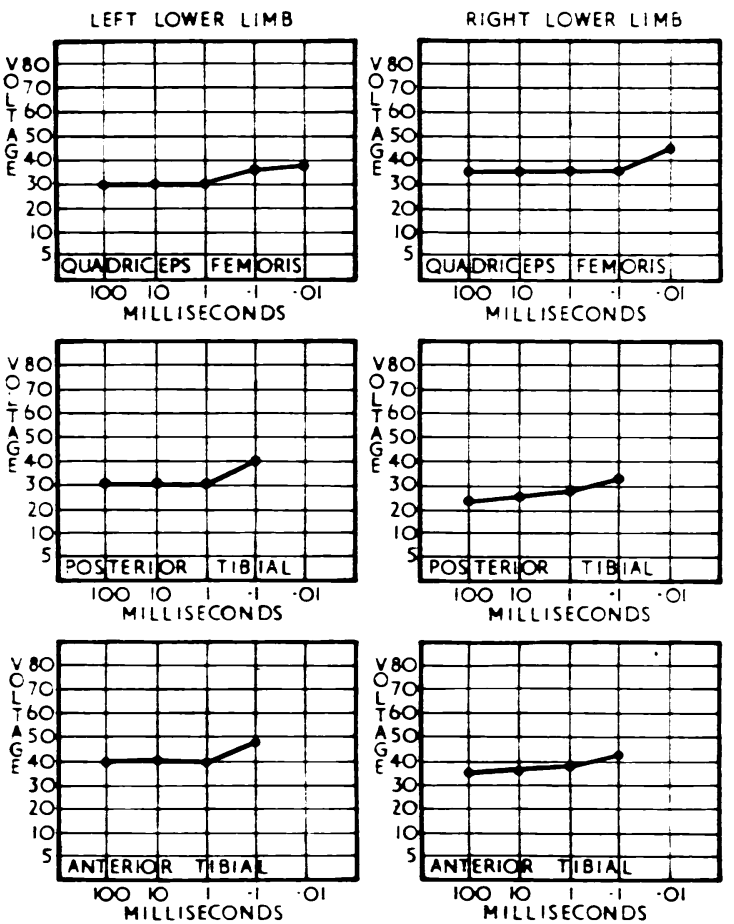

Fig. 2.-Electrical reactions of affected muscles.

BLoOD. The Wassermann reaction was negative, as also was the syphilis flocculation reaction.

Urea nitrogen was $16 \mathrm{mg}$. \%; blood cholesterol $154 \mathrm{mg}$. \%; serum calcium, $10.4 \mathrm{mg}$. \%; serum alkaline phosphatase, 7 units (King); serum creatinine, $0.5 \mathrm{mg}$. \%; serum inorganic phosphate (as P), 4.7 mg. \%.

URINE. A 24-hour specimen (volume $390 \mathrm{ml}$.) gave total creatinine, $183 \mathrm{mg}$.; total creatine, $402 \mathrm{mg}$. (as creatinine).

Muscle Reactions. There was a poor response of affected muscles to faradism (Fig. 2). No R.D. present.

$A$ radiograph of the skeleton showed general bony decalcification, and spindling of the shafts of the long bones. The right humerus showed cystic changes at the proximal extremity of the shafts. The pipe-stem appearance of the humeral shaft is readily seen in Fig. 3.

Histology. Biopsy was carried out on two occasions, the tissue being obtained from the left sartorius, the right and left gastrocnemii, and the left triceps. In all cases there was marked resistance to the knife, almost amounting to a grating sensation, especially when the right gastrocnemius specimen was excised. The muscles were pale and firm in texture.

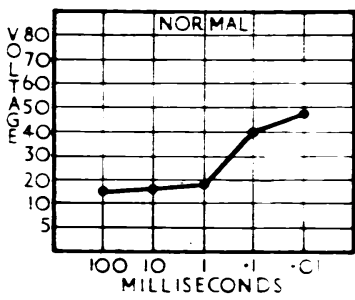

Biopsy material from the four muscles excised was examined. The pathological changes in all were of a similar type but differed in degree. They consisted of degeneration proceeding to disappearance of muscle fibres, and replacement by fibrous and fatty tissue.

The muscle fibres varied greatly in size and staining reaction. Some had undergone hyaline necrosis: they stained vividly with eosin, and had completely lost their cross-striation. Some of these hyaline fibres were much larger than normal; others were abnormally small. Other fibres stained faintly with eosin. Most of these showed unusually conspicuous longitudinal striation and had lost their cross-striation, but in a few fibres the transverse markings remained clear. These pale fibres also varied greatly in size. In the more severely affected muscles, there had been a great loss of muscle fibres: the bundles had been broken up, some being

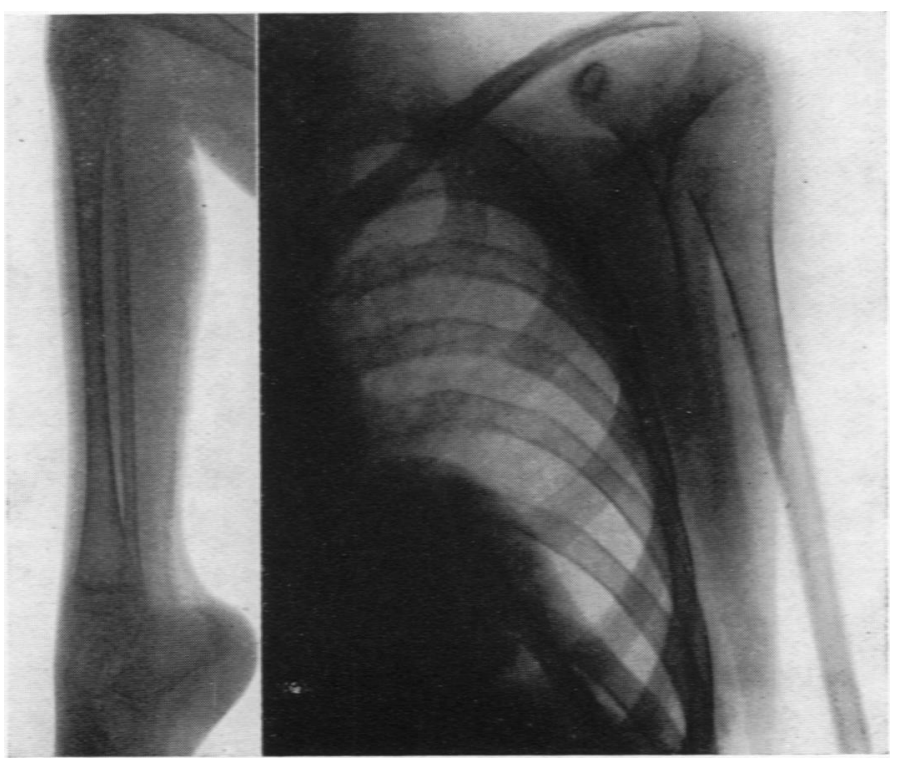

Fig. 3.-Radiographs showing 'pipe-stem' appearance of the shafts of long bones. 


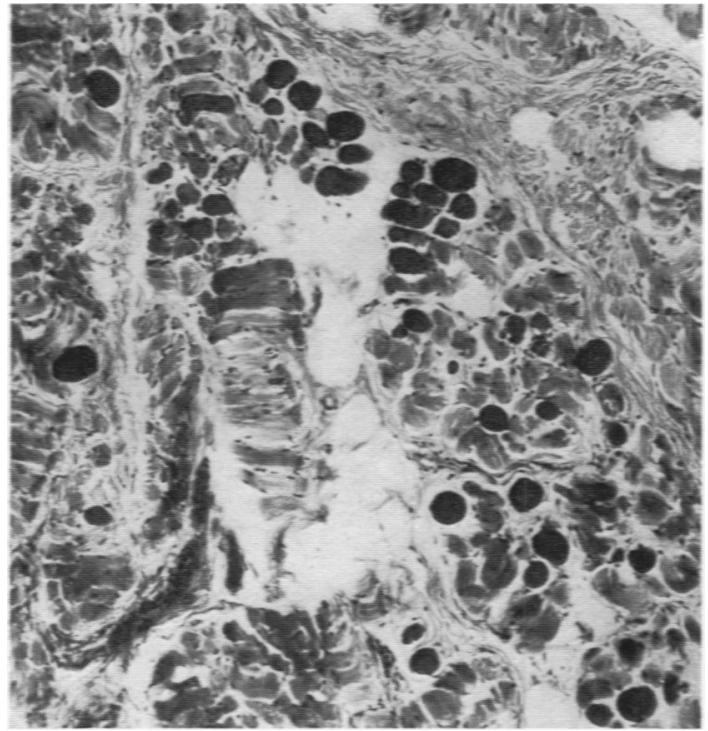

Fig. 4.-Photomicrograph of left gastrocnemius showing some loss of muscle fibres, hyaline necrosis and variation in size of muscle fibres, slight fibrosis and fatty infiltration (haematoxylin and eosin $\times 85$ ).

represented by only a few, or even by single, muscle fibres (Fig. 5).

Replacement of the lost muscle fibres was partly by fibrous tissue, partly by fat. Fibrous replacement occurred by means of the development of fibrous tissue between the atrophied muscle fibres (Fig. 6) and, in addition, in some parts, collagen fibres appeared to have

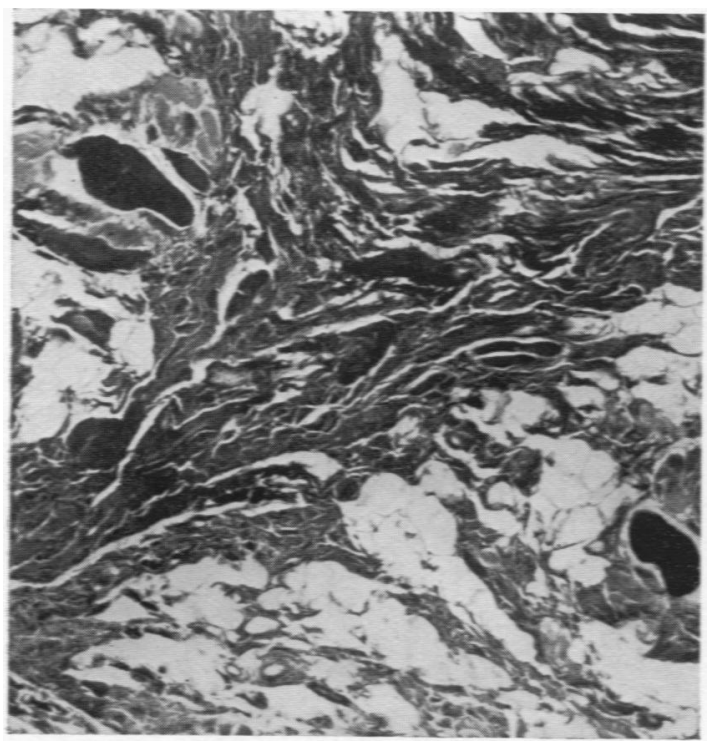

FIG. 6.-Photomicrograph of triceps showing widely separated hyaline muscle fibres (some very large), dense fibrosis, and some fatty infiltration (azan $\times 65)$.

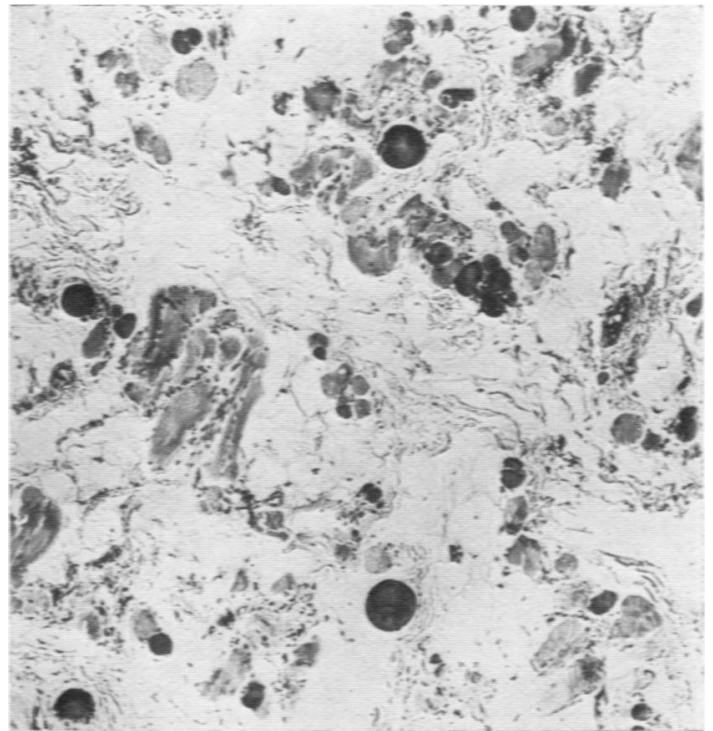

FIG. 5.-Photomicrograph of right gastrocnemius showing more advanced stage with great loss of muscle fibres, hyaline necrosis and variable size of muscle fibres. Replacement is mainly by fatty tissue (haematoxylin and eosin $\times 65)$.

replaced some or all of the muscle fibrils within theo of sarcolemma sheath so that the outline of the replaced i muscle fibres was retained. In some parts the atrophieto muscle bundles, and even individual fibres within the? bundle, were separated by loose connective and adipose tissue, without dense fibrosis.

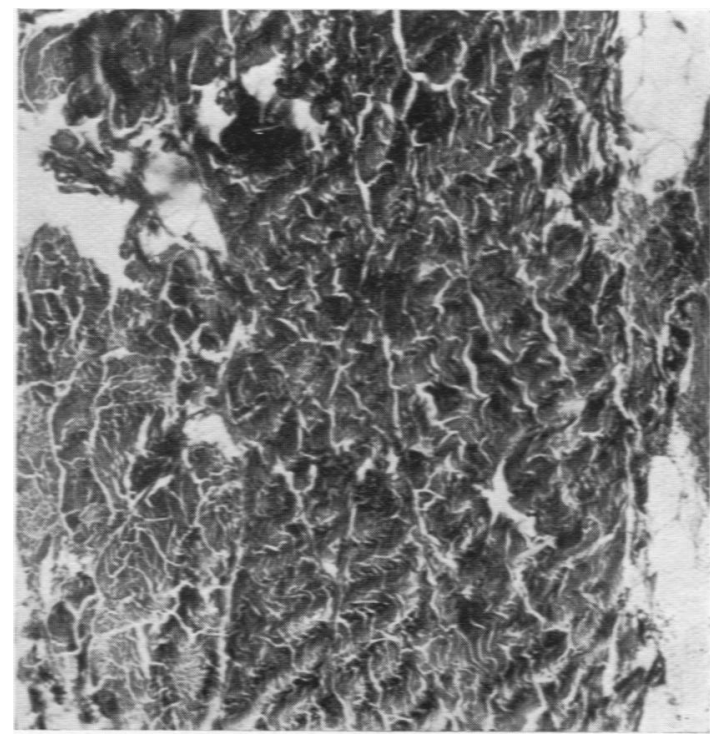

FIG. 7.-Photomicrograph of sartorius showing almost complete replacement of muscle by dense fibrous tissue and slight fatty infiltration (azan $\times 100)$. 
The sarcolemma nuclei were unusually conspicuous, especially where fibrous replacement was in progress, and the new fibrous tissue contained many plump fibroblasts, but there was no lymphocytic or other inflammatory cell infiltration in any of the sections, except a collection of lymphocytes surrounding a small blood vessel in the muscle that was at the earliest stage of degeneration among those examined (left gastrocnemius).

The degeneration was most advanced in the sartorius muscle, where only traces of muscle remained, and replacement was partly by dense fibrous tissue and partly by fat (Fig. 7). In the left triceps the changes were identical except that they were not quite so far advanced. In both gastrocnemii, replacement was mostly by fatty tissue and there was no dense fibrosis. The process was considerably more advanced in the right than in the left gastrocnemius.

Active treatment was not adopted, as the process was considered to be so advanced that any orthopaedic procedures would be of little benefit. The child was discharged from hospital on July 25, 1949; his weight on discharge was $15 \cdot 4 \mathrm{~kg}$.

He was seen again on November 16, 1949, when it was found that all the affected muscles were much softer and the degree of movement of the joints of the upper limbs, especially the elbow joint, had increased. He was still unable to sit up and to feed himself but was using his fingers more freely. There was no further involvement of other muscle bellies.

\section{Discussion}

The essential features of myositis fibrosa generalisata have been clearly enumerated by Somers in 1939. These are the insidious onset, the progressive nature of the disease, the absence of facial and sphincter involvement, the afebrile course, the sand-bag feeling of the more severely involved muscles, and the typical histopathological findings.

We have been unfortunate in not obtaining a more detailed history from the mother especially as to whether the child had complained of stiffness of the limbs. To the best of our knowledge the course of the disease has been painless and unaccompanied by fever. The disease appears to have begun in the left arm and, between the age of 5 years and the time of admission, the other limbs have also become involved. There is no doubt that the texture of the muscle is similar to that found in typical cases of myositis fibrosa generalisata. On admission, the appearance of the child closely resembled that of the photograph of Batten's case in 'Diseases of Children' (in Garrod, Batten, and Thursfield, 1949). In common with other reported cases there was no evidence of involvement of the central nervous system or of the skin. The electrical responses of the muscles showed no reaction of degeneration.

Typical degenerative changes were found in the muscle fibres. The amount of fibrous tissue replacement was less than has been reported in many other cases, and infiltration of the degenerated muscle by fatty tissue was more prominent. This feature is not referred to in previous case reports, but its presence is obvious in the illustration of the case reported by Burton, Cowan, and Miller (1923). Round-cell infiltration was almost completely absent. In this respect our case differed from the cases reported by Litchfield (1903), Burton et al. (1923), Schwab et al. (1932), Blau (1938), and Strong (1949), but resembled those reported by Janicke (1895), Batten (1904), Price (1930), and Ornsteen (1935).

The histological features were thus sufficiently distinctive to justify the inclusion of the case in the category of myositis fibrosa generalisata.

Further support for this diagnosis was provided by a study of the creatine metabolism, by means of which the extent of muscle degeneration can be judged. Children normally excrete creatine in the urine owing to their inability to store it. The creatine output, however, ceases about the age of puberty (Marples and Levine, 1936). Creatinine excretion in the urine increases during infancy and childhood. According to Behrendt (1949) a child of 11 years excretes about $2 \cdot 7 \mathrm{mg}$. per $\mathrm{kg}$. body weight of creatine and $20 \mathrm{mg}$. per $\mathrm{kg}$. body weight of creatinine in 24 hours.

In our case the urinary creatine output was $402 \mathrm{mg}$. in 24 hours and of creatinine $183 \mathrm{mg}$. Our patient weighed about $15.4 \mathrm{~kg}$. The normal daily creatine excretion for this child of 11 years should, therefore, be $41.6 \mathrm{mg}$. and that for creatinine should be $308 \mathrm{mg}$. It is thus evident that there is a gross excess of creatine excretion with a corresponding diminution in creatinine output. This indicates an extensive degree of muscle destruction and degeneration.

Schwab et al. (1932) found that creatinuria was a notable feature of the disease, more than $40 \%$ of the total creatine being excreted as creatine even with a meat-free diet. Biochemical analysis of the muscle specimen obtained from their patient showed an unusually low creatine content. Those muscles exhibiting microscopical evidence of marked inflammatory changes had the lowest creatine content, but this amount was reaching saturation point for the affected muscle. Treatment with glycocol in an attempt to restore creatine content of muscle is, therefore, unlikely to have much beneficial effect. It is important to realize that there is no skin involvement, distinguishing it clearly from dermatomyositis. This excludes cases described by Nixon (1907), Taussig (1932), and Cross (1934).

Little is known concerning the aetiology of 
myositis fibrosa generalisata because of its infrequent occurrence. There does not appear to be any hereditary or familial diathesis. Batten (1904) considered that there might be some relationship to the more common condition of myositis ossificans progressiva, and this was considered not impossible by Schwab et al. (1932) who pointed out that ossification of muscle tissue was preceded by myositis in almost every case. However, to our knowledge, no case of myositis fibrosa generalisata has been found to progress to myositis ossificans. Jendrassik (1911), quoted by Blau (1938), considered the disease to be a special type of degenerative myopathy. Blau himself thought that it was probably related pathogenetically to the localized myositides.

There is considerable difference of opinion amongst authors regarding the inflammatory nature of the disease. Most authors regard round-cell infiltration as evidence of inflammation, but such infiltration has not been a constant feature in reported cases. The afebrile course of the illness provides no evidence of an infective origin, and the round-cell infiltration may well be a reaction to the presence of degenerating muscle fibres. It may be a transient phenomenon, present only at certain stages of the pathological process.

A comparison between myositis fibrosa generalisata and progressive muscular dystrophy reveals many similarities, although some authorities consider that there is little difficulty in distinguishing the two conditions. Macroscopically, in both diseases the muscles are pale and firm, differing only in degree. Microscopically, in both, the muscle fibres vary in size, some being larger and others smaller than normal. In both, they show hyaline and fatty degeneration, loss of cross striations, and ultimate disintegration. In progressive muscular dystrophy there is an increase in the number of sarcolemma nuclei. This feature has not been described in previous cases of myositis fibrosa progressiva, but it was present in our case. In progressive muscular dystrophy the replacement of the lost muscle fibres by fatty tissue is much more characteristic than in myositis fibrosa generalisata, but in the later stages fibrosis supervenes and produces a condition closely resembling that of myositis fibrosa. In our case, the combination of fatty infiltration of the less severely affected muscles, and fibrosis of those at a later stage of the disease, was a further point of resemblance to progressive muscular dystrophy. It is evident, therefore, that the pathological changes in the two diseases closely resemble one another, and differ in degree rather than in kind.

Radiological changes in the long bones in progressive muscular dystrophy were described by Epstein and Abramson (1941). These included symmetrical diminution in the size of the scapulae, a large humeral head in relation to a small, shallow glenoid fossa, and slender humeral shafts giving a 'pipe-stem' appearance. The latter radiological changes were present in our case.

We consider that our case, which most closely resembled myositis fibrosa generalisata in its principal clinical and pathological features, and yet had certain points of resemblance to progressive muscular dystrophy, may be regarded as providing some evidence to suggest that myositis fibrosa generalisata is one form of progressive muscular dystrophy, and is essentially a degenerative, and not an inflammatory, lesion of the muscles. This is in agreement with the opinion of Jendrassik (1911).

\section{Summary}

The symptomatology and pathology of recorded cases of myositis fibrosa generalisata is presented, and an additional case is described.

There is evidence to suggest that the disease is not a separate clinical and pathological entity, but one form of progressive muscular dystrophy.

We wish to thank Dr. A. B. Donald, Medical Superintendent of the Western General Hospital, Edinburgh, fore referring this case : Mr. J. J. Mason Brown for permission to publish this article : and Miss C. Brydone, of the Department of Clinical Photography, Royal Hospital for Sick Children, Edinburgh, who took the photographs.

\section{REFERENCES}

Batten, F. E. (1904). Trans. clin. Soc. Lond., 37, 12. In Garrod, A. E., Batten, F. E., and Thursfield, H.' (1949). 'Diseases of Children,' 4th ed., vol. 2, p. 273. London.

Behrendt, H. (1949). 'Diagnostic Tests for Infants and Children,' p. 173. New York.

Benedek, L. (1944). Mschr. Psychiat. Neurol., 109, 93. Berghman, G. (1874). Svenska LäkSällsk. Förh., p. 107. Abstr. Zbl. Chir. (1874), 1, 618.

Blau, A. (1938). J. Mt Sinai Hosp., 5, 432.

Burton, J. A. G., Cowan, J., and Miiler, H. (1923). Quart. J. Med., 17, 103.

Cross, A. G. (1934). Lancet, 2, 1104.

Ellermann, M. (1943). Acta psychiat. Kbh., 18, 411.

Epstein, B. S., and Abramson, J. L. (1941). Arch. Neurol. Psychiat., Chicago, 46, 868.

Gies, T. (1879). Dtsch. Z. Chir., 11, 161.

Gowers, W. R. (1899). Brit. med. J., 1, 65.

Hoover, C. F. (1924). Tice's 'Practice of Medicine,' Vol. 6, p. 543. Hagerstown, Maryland, U.S.A.'

Janicke, O. (1895). Dtsch. med. Wschr. (VereinsBeilage), 21, 117.

Jendrassik, E. (1911). Cited by Blau, A. (1938).

Kagan, L. (1936). Jb. Kinderheilk., 147, 207.

Kreiss, A. (1886). Berl. klin. Wschr., 23, 877.

Litchfield, W. F. (1903). Aust. med. Gaz., 22, 516. 
Marples, E., and Levine, S. Z. (1936). Amer. J. Dis. Schwab, E. H., Brindley, P., Bodansky, M. and Harris, Child., 51, 30.

Nixon, J. A. (1907). Lancet, $1,79$.

Ornsteen, A. M. (1935). Ann. Surg., 101, 237.

T. H. (1932). Ann. intern. Med., 6, 422.

Price, I. I. (1930). Brit. med. J., 1, 1131.

Rosenstirn, J. (1918). Ann. Surg., 48, 485.

Somers, D. C. (1939). J. Bone Jt Surg., 21, 414.

Strong, J. A. (1949). Ann. rheum. Dis., 8, 158.

Taussig, L. (1932). Arch. Derm. Syph., Chicago, 25,

Schüller, A. (1903). Jb. Kinderheilk., 58, 193. 882. 